\title{
Is Autonomy Imposing Education Too Demanding? A Response to Dr. De Ruyter
}

\section{Citation}

Levinson, Meira. 2004. Is Autonomy Imposing Education Too Demanding? A Response to Dr. De Ruyter. Studies in Philosophy and Education, 23, no. 2-3: 223-233.

\section{Published Version}

doi:10.1023/B:SPED.0000024424.69307.07

\section{Permanent link}

http://nrs.harvard.edu/urn-3:HUL.InstRepos:10860777

\section{Terms of Use}

This article was downloaded from Harvard University's DASH repository, and is made available under the terms and conditions applicable to Other Posted Material, as set forth at http:// nrs.harvard.edu/urn-3:HUL.InstRepos:dash.current.terms-of-use\#LAA

\section{Share Your Story}

The Harvard community has made this article openly available.

Please share how this access benefits you. Submit a story.

Accessibility 


\section{Response to Doret de Ruyter, “Is Autonomy Imposing Education Too Demanding?” Meira Levinson}

I would like to start by thanking Doret de Ruyter for her fair and thoughtful review of my book, The Demands of Liberal Education, as well as thanking Studies in Philosophy and Education for allowing me the opportunity to respond to her comments. It's always exciting for an author to engage with others who have read one's work carefully and who take one's ideas seriously. De Ruyter is an ideal reader in this respect, insofar as she is simultaneously sympathetic and critical. Hence, my disputes with her stem almost entirely from substantive disagreements with her positions rather than from any sense that she has misunderstood or inaccurately described my aims or arguments. The only exception is one small quibble with the introduction, in which de Ruyter characterizes my purpose as exploring "whether it is still possible to develop a position with regard to education and the role of the state which has sufficient plausibility that will be acceptable to most people, even given the differences in opinion.” I just wish to clarify that I'm developing this position within the context of liberalism, and that I don’t expect all people are or will become liberals. Since nothing in the rest of de Ruyter's review contradicts or takes issue with this approach, I don't think anything else in the review rides on this slight mischaracterization; I mention it only to clarify my purpose to readers who may not have read (or remembered) that part of my book.

Although de Ruyter and I do have points of agreement, I will focus my reply on some significant and substantive disagreements we have about the nature of autonomy, about parents' duties or privileges concerning their children's education, and about the characteristics of the school community that are required to ensure that all children develop their capacities for autonomy. For the sake of simplicity and clarity, I will follow de Ruyter's organization of these 
topics, including using her headings to indicate at which section of her review each of my responses is directed. I diverge from this approach only at the end of my response, at which point I pick up on two points she makes in two different sections of her review in order to explain the extent to which I agree with her and discuss the implications I think these criticisms have for my theory of liberal education provision.

\section{Autonomy}

I begin, as de Ruyter does, with the concept of autonomy. In her discussion of the ideal of personal autonomy, de Ruyter notes this ideal “does not mean that every option should be open or can (psychologically) be considered by an autonomous person.” Although I think that this is generally right, I suggest that the examples she gives fail to uphold her point, and in fact reveal a significant shortcoming in her understanding of autonomy, critical self-evaluation, and value hierarchy. Although she rescues her analysis to some extent in noting that autonomous people may subscribe to "ultimate values” that necessarily guide the plurality of lower-level values to which they adhere, I show that she again gets off track by emphasizing that such ultimate values could not be reevaluated on "an equal basis" with others.

First, while I agree with de Ruyter that some (even many) actions and life options may rightly be "beyond the pale” even to autonomous people, de Ruyter’s examples both fail to illuminate this point and misconstrue the relationship between autonomy and constitutive values. Many autonomous people might rightly consider it unthinkable to abuse a child, to collaborate in a scheme that defrauds poor people, or to destroy the environment. These are plausible bedrock (or as she terms them, “ultimate”) beliefs, and even if a person holds a number of these (and hence has a plurality of values), it would be reasonable to say, as de Ruyter does, that "changing them or losing them would imply a profound change of her identity.” There may nonetheless be 
times, however, when such an individual is forced to rethink these bedrocks. Under a particularly cruel dictator, for example, she may have to weigh her opposition to abusing a child or destroying the environment against her interest in remaining alive. To some extent, her ability to weigh these two options is a measure of her autonomy, even though her effective autonomy is obviously extremely restricted under these conditions, and even though no matter what she decides, she would probably say that her sense of self has been profoundly changed.

More to the point, our autonomous exemplar must also be able to face up to potential conflicts among or reformulations of her values under less drastic circumstances. For example, a lottery is arguably one means of defrauding poor people. But it is also a windfall for government revenues, and hence promotes government expenditures — including on social services, children's services, and the environment. No matter which position she ultimately takes on government-sponsored lotteries, our exemplar can justifiably claim to be fully autonomous only if she is able to think through the question and weigh the various arguments for and against. In addition, she needs to be open to potential reformulations or modifications of her bedrock beliefs in response to new information or new situations. For example, does spanking constitute child abuse? Many people who are (and always have been) opposed to child abuse would have said “no” thirty years ago but “yes” today. In regard to the environment, would she judge a wind farm to be destructive or constructive? If constructive, how would she feel if the wind farm were built half a mile from her house, destroying her previously unsullied view of the ocean or the mountains? Might she start giving more credence to her neighbors’ arguments about the importance of the "aesthetic environment”? How might this influence her bedrock opposition to 
destroying the environment? ${ }^{1}$ As I hope I’ve made clear, even bedrock or “ultimate values” need to be open to evaluation, reconsideration, and judgments about their appropriate application.

De Ruyter may object that my arguments above show that “ultimate values” are complex, and that their appropriate application takes thought and care, but not that they can or should be seriously challenged, or that individuals must therefore be “open” to “every option.” I would agree with this argument to some extent, and I certainly agree that such basic ethical commitments as opposition to child abuse or fraud may be constitutive of one's identity. This is not to say, however, that autonomous people may close off multiple avenues of possibility at every level of action. On the trivial side, I'm sure that many people who said ten years ago, in the equivalent of de Ruyter's yellow leather couch example, “You'll never catch me dead in bell bottoms! What were people thinking in the 70's?” are now wearing bell bottoms. Fashions change, and hence (for better and for worse) so do people's judgments. Although it's true that being autonomous doesn’t entail one’s always considering every option, it does mean being flexible enough so that when circumstances demand it, one is able to consider options one might have rejected before.

This is true not only in trivial cases such as fashion (or should I say in deep cases such as aesthetic judgment?), but also in cases such as political affiliation, which is de Ruyter's second example. She states that although "it is completely impossible for me to seriously consider the option of voting for a right-wing party,” she is nonetheless a "truly autonomous person.” Here I think that the truth of her claim depends on how "impossible" it would really be. For example, I would normally say the same for myself, that I could not conceive of voting for a right-wing party. But consider the hypothetical situation of John McCain and Colin Powell (both

\footnotetext{
${ }^{1}$ I introduce this example because such a wind farm is currently a subject of hot contestation among a number of self-professed environmentalists and environment-loving residents of Cape Cod, Massachusetts.
} 
Republicans) running for president and vice president of the United States in 2008 against Joe Leibermann and Zell Miller (both Democrats). Under these unlikely but not outlandish circumstances, I could conceive of myself voting Republican — despite, or perhaps because of, my viewing my liberal values as things I'm deeply, even fundamentally, committed to. If I couldn't seriously consider the option of voting for the Republicans under this scenario, in fact, I think one could properly question whether I was truly autonomous, insofar as McCain/Powell conceivably would promote some of my deepest values (electing an African-American vice president, supporting campaign finance reform, reducing corporate power over governmental affairs, even promoting some social programs) more than Liebermann/Miller would do (they are two right-wing hawks who inject religion where it doesn’t belong and sell out government to corporate interests). Happily for her, de Ruyter is not faced with some do the disastrous choices that bedevil the American electorate, and hence maybe her opposition to right-wing parties may never be tested; I hope for her sake and that of her country that it's not (i.e., I hope that the leftwing parties in her country never field a dire, even despicable, roster of candidates). But if it is, and if she still insists that it would be "impossible” even to "seriously consider" voting for a conservative party or candidate, then I would challenge her claim that she is nonetheless "truly autonomous.”

Essentially, autonomy is a capacity or characteristic that comes into play for many adults at times of tension or conflict. In the course of day-to-day life, when things are going well, there's no need or reason to shake up one's commitments or to question one's values. For most of us, a life in which we were constantly interrogating our decisions, evaluating our life choices, and questioning our identities would be an unhappy and even unfulfilling one. This is not what autonomy requires (although it is certainly compatible with such a life). All adults and children, however, do encounter circumstances when, if we're being honest with ourselves, we discover 
either that two values we hold potentially conflict, or that one of our values turns out to be questionable for some other reason. I gave examples of such circumstances above. Under these circumstances, enacting our autonomy would entail questioning our values or judgments. Such questioning need not take place “on an equal basis,” I agree; nowhere in my book do I suggest that all values can or should be reevaluated on an "equal basis.” When one's belief in friendship runs up against one's commitment to one's family, it may be a "no-brainer" for many people to prioritize the latter over the former. But even the latter commitment needs to be examined, if only to be thoughtfully affirmed — “yes, this is fundamental to my self-concept.” And, it may turn out on occasion that such moments of self-questioning will lead one to conclude that one is a different person than one believed: that what appeared fundamental to one's sense of self wasn’t, or has been superceded by something else.

\section{Parental duties and rights regarding the education of children}

In contrast to de Ruyter’s first section on autonomy, about which individuals may have reasonable disagreements, I frankly think this second section is confused — not in its characterization of my arguments, but in its own delineation of parental duties. I begin with a small point of formal logic related to de Ruyter’s summary of Hohfeld's argument. In contrast to de Ruyter's assertions, the claim that (A) it is "a logical contradiction for a person to have a duty as well as a privilege to do $x$ " is logically distinct from the claim that (1) "when one has a privilege to do $\mathrm{x}$, one does not have a duty not to do x." It is also logically distinct from the claim that (2) "when one has a duty to do x, one cannot at the same time have a privilege to abstain from performing the duty.” (1) and (2) follow not from (A) but from (A'): It is a logical contradiction for a person to have both a duty to do $\mathrm{x}$ and a privilege not to do $\mathrm{x}$, or a privilege to do $\mathrm{x}$ and a duty to do not-x. A', however, may be false insofar as the relational aspect of the 
duty and privilege have not been specified. Although it's logically true that I can't both have a privilege given by my neighbor to enter her garden and a duty to her not to enter her garden, it's logically possible that my neighbor could confer on me the privilege to enter the garden, but I would nonetheless have a duty to my sister not to enter the garden (because, say, I promised her I would not). Because de Ruyter neglects the relational aspects of duties and privileges whereas by Hohfeld's lights, a duty is always held in relation to someone — she claims an independence between duties and privileges that may not exist.

This issue relates to my more substantive objections to de Ruyter's characterization of the nature and extent of parents' duties toward children, which I think is based on two unjustified assumptions. Her first unjustified assumption is that parents have the duty to educate their children. Although I would certainly agree that children living in liberal, industrialized societies have a right to an adequate education — and more particularly, as I argue in Demands, a right to an autonomy-promoting education — it's not at all clear to me that children possess this right against their parents. In other words, I'm not convinced that parents in particular are the ones who have the duty to satisfy children's right to education. As I argue in my book, children’s rights to an autonomy-promoting education derive from the liberal state's commitment, within the context of deep pluralism, to particular procedures, institutions, and legitimating conditions that presuppose the value of (and end up establishing rights related to) adults' exercise of autonomy. Insofar as it is the duty of the state to its citizens to establish the conditions and protect the freedoms necessary to enable adults to exercise autonomy, it is also the state's duty to children to help them develop the capacity for autonomy. As a result, I just don’t see how parents come into play here. It does strike me as plausible to assume that parents have the duty of preparing their children for schooling - e.g. by feeding them breakfast daily, providing them a quiet place to work in the afternoons or evenings, ensuring that they get to school daily — as 
well as the duty to put reasonable effort into ensuring that their children receive an adequate education - e.g. by pressuring the school, district, or state authority to improve the schools, or by working with their children's teachers to resolve problems that arise. But it seems rather implausible to say that parents have the "duty to educate their children.”

De Ruyter's second unjustified assumption is an even less convincing extension of the first: namely, that parents have the duty to educate their children specifically in light of their own convictions about what is in their children's best interests. I don't see why de Ruyter thinks this assumption is justified at all. Even if parents did have a duty to educate, de Ruyter gives no argument or evidence to support the claim that their duty is to educate "according to their [the parents'] conviction what is in the best interest of the child.” Why should the parents' views about their children's best interests trump society's views, or those of the state, or of experts in the field, etc.? A positive argument needs to be given to support this claim, and de Ruyter gives none. By contrast, as I discuss in chapter 2 of The Demands of Liberal Education, there is a good argument to be made in support of the claim that within a liberal context, at least, it is in children’s best interests to develop the capacity for autonomy. Regardless of parents', society’s, experts' or others' opinions, therefore, whoever has the duty to educate children has the duty to educate them so that they develop the capacity for autonomy.

\section{Detached Schools and Conclusion}

Although de Ruyter doesn’t seem to realize it, this issue of rights and duties — especially duties of whom, to whom, to do what — is also central to my justification of and insistence about the detached school. De Ruyter begins this section by asking, “(a) are these [detached] schools necessary for the development of autonomy?” Although this is an important question, it needs to be rephrased in one significant respect, at least to stay true to the justification I give in my 
book for detached schools. Question (a) should read, “Are these schools necessary to ensure children's development of autonomy?" This is a crucial addendum. The point is not to ask whether detached schools are necessary in all circumstances for the development of autonomy. Given human beings’ diverse range of talents, experiences, and resources, individuals may and often will develop autonomy under a range of indifferent or even hostile circumstances. Some children could probably develop autonomy while being raised in a shoe box; more to the point, I readily admit that many children do develop autonomy while attending a whole range of schools (including many schools that seem purpose-built to stifle autonomy) thanks to a variety of other, non-school-based influences. So I fully agree that many children will develop the capacity for autonomy without ever entering a detached school. But the fact that some or even many children may and will be able to do so is not the point. Insofar as the state has a duty to all children to ensure that they all have the opportunity to develop their capacities for autonomy, it must put a public policy into place that will help it discharge its duty. This means it must make sure that all children are enabled to develop their capacities for autonomy, not just the lucky some (or even many) who happen to encounter people, institutions, books, or other influences that promote their autonomy. The detached school is the public policy that is most likely to help all children develop autonomy without infringing on other rights (such as adults' rights to control their home lives) within the liberal state. Hence I argue that the detached school is obligatory - even if many children would likely develop their capacities for autonomy in its absence.

I should note also that my conditional support for religiously affiliated schools does not contradict my insistence on detached schools. The religiously affiliated schools I support are those that are pluralistic and diverse — including being diverse along religious lines. Although this may seem paradoxical, it describes many Catholic, Anglican or Episcopal, and Quaker 
schools in Britain and the United States. ${ }^{2}$ My support for religious schools under certain conditions, therefore, neither contradicts nor supervenes my insistent support for detached schools. De Ruyter is hence wrong to conclude that "it is not detachment per se that is important.”

Furthermore, even if religious schools could and do promote children's development of autonomy, thanks to the diverse composition of their student body and faculty, their curriculum, etc., I disagree with de Ruyter that a liberal state could simultaneously support these schools while banning fundamentalist schools — at least not in a society in which religion is socially divisive. From a public policy perspective, how would one legislate against certain kinds of religious schools and for others, especially given the need to treat all religions equally per liberal principles? Formal accountability mechanisms could not be sufficient, insofar as many schools’ admissions or teacher hiring policies, for example, may be formally neutral and in accordance with detached school principles, but nonetheless have substantially divisive and/or discriminatory results, especially in a context in which religion is socially divisive. Many

\footnotetext{
${ }^{2}$ For example, a study of private schools in the United States documented that neither Friends schools nor Episcopal schools generally even take religious affiliation into account in their student selection process, and also do not rate it as their most important goal. In 1993-94, zero percent of Friends elementary schools and 2.6\% of Episcopal elementary schools (compared with five and 1.9 percent of Friends and Episcopal high schools, respectively) included religious affiliation as an admission requirement at all. Reflecting this apparent lack of religious focus, only $1.6 \%$ of Episcopal schools and $11.6 \%$ of Friends schools rated “religious development” as their most important educational goal, and well under half of these schools rated it as even one of their three most important educational goals. Given that most of these schools thus neither select students according to religious affiliation nor emphasize religious belief within the curriculum, it would be fair to surmise that many Friends and Episcopal religious schools, at least, might exhibit significant religious diversity. (See Private Schools in the US, Tables 2.3a, 2.3b, 4.1, and 4.2.) I have been unable to find similarly detailed data for voluntary-aided religious schools in England, but I know anecdotally of many state-funded, diverse, religious schools. One piece of data may shed some light on this phenomenon. In the borough of Blackburn with Darwen, eight out of nineteen Church of England primary schools in 2001 actually served a majority Muslim population, and many parents "positively wanted multi-cultural, multi-faith schools." (See Blackburn with Darwen Borough Council (2003).)
} 
schools could officially have an open admissions policy, accepting students regardless of their religious affiliation, but teach a religious curriculum that is so evangelical that non-evangelical Christian families would never send their children to the school. Such a school would fail to create an autonomy-promoting community despite satisfying many of the formal requirements I discuss in Demands. To the extent, however, that states would consequently have to assess religious schools on substantive rather than merely formal grounds in determining whether to support or ban them (at least in societies in which religion was socially divisive), then the liberal state would soon be caught up in a public policy nightmare — as well as eventually in a crisis of legitimacy. As a matter of public policy, therefore, liberal states cannot permit schools to differentiate and affiliate themselves on socially divisive grounds, even if some fraction of schools thus affiliated might nonetheless provide students an autonomy-promoting education.

This reminder, that under my plan a number of schools that currently exist would simply be outlawed, serves also as a response to de Ruyter's concluding criticism of my position. De Ruyter argues that my insistence on an autonomy-promoting education for all children, and my unwillingness to compromise those educational aims in deference to, for example, fundamentalist parents' concerns, ends up being self-defeating. Because parents will be unable to hammer out accommodations that would encourage them to keep their children in the local public schools, she suggests, they will end up withdrawing their children and placing them in “fundamentalist private schools” that clearly will promote children’s development autonomy much less than any diverse public school, even if the latter has had to make accommodations such as modifying the curriculum in order to keep the fundamentalist families satisfied. De Ruyter is right that this is a real risk - if such private schools exist. That is why as a practical matter in today’s context, I might have encouraged the school district to go further in accommodating the parents' wishes, so that their children weren't removed from the public 
school setting. But under the liberal educational ideal I lay out in Demands, no such things as private (or public) fundamentalist schools would exist. The liberal educational ideal permits, and could even conceivably encourage, private schools — but only those that promote children’s development of autonomy, are detached, have open admissions policies, etc. It does not permit either homeschooling or non-autonomy-promoting schools. Hence, my policy would not be selfdefeating, because there would be no schools to which the fundamentalist parents could retreat. All would be autonomy-promoting.

Although I think that most of de Ruyter's challenges to the liberal educational ideal ultimately fail, I do wish to acknowledge two important criticisms she makes that do stand up to close scrutiny. First, de Ruyter is right to note that it is implausible to think that "there exists something like a public culture, called civic identity, which though common to all is detached from most local cultures.” It's clearly true, as she argues, that local cultures, beliefs, and ways of doing things must combine to create a larger civic culture, and hence that it's impossible to have a school grounded in the civic culture that is fully detached from local commitments. I don't think (nor does de Ruyter seem to think) that this is a devastating critique of the detached school. But it is worth noting and acknowledging.

More importantly, in the section on detached schools, de Ruyter points out that my ideal of a detached liberal school is just that: an ideal. What I propose is idealized in theory, and it doesn’t exist in practice. Her criticisms, therefore, of the contrast I draw between the theoretical strengths of my liberal school ideal and the empirical failings of other school policy and choice initiatives are well taken. To my own detriment, I would even push her criticism about the empirical assessment of the liberal school ideal much further than she does. As I note in my paper “Assessing Autonomy” (2001), it is probably impossible to assess whether schools are doing a good job of fostering children’s development of autonomy: a valid and reliable 
assessment of autonomy would "require a mammoth infrastructure that itself is probably impossible to realize successfully"; furthermore, even if such an assessment could be realized, it would likely "be self-defeating by reorienting education from teaching to testing, and from fostering autonomy to fearing accountability.” Thus, I not only agree with de Ruyter that my proposals benefit in comparison with the competition partly because they have not been put to empirical test, but also acknowledge that it's unclear how one would even evaluate their success once they were implemented insofar as a standardized “autonomy assessment” is probably impossible.

This criticism brings us back to the issue of formal versus substantive accountability that I introduced above; in this case, the challenge of implementing a substantive system of assessment poses difficulties not just for religious schools (or, more generally, for schools aligned with socially divisive conceptions of the good), but for all schools. I have not yet figured out how to address this challenge — in the meantime, however, I still think I have presented a compelling case for liberal states' responsibility to help all children develop their capacities for autonomy via regulating schools. Although I thank de Ruyter for her thoughtful and focused criticisms, I don't think that they succeed in seriously challenging either the thesis or the conclusions of The Demands of Liberal Education.

\section{Bibliographic References}

Levinson, M. (2001) Assessing Autonomy. Unpublished manuscript. Presented at the Annual Meeting of the American Political Science Association, San Francisco, CA, August 30 September 2, 2001.

Hofeld, W. N. (1919) Fundamental Legal Conceptions as Applied in Judicial Reasoning. New Haven, CT: Yale University Press.

US Department of Education, National Center for Education Statistics. (2000) Private Schools in the United States: A Statistical Profile, 1993-94. 
Blackburn with Darwen Borough Council. (2003) Faith Schools and Cultural Diversity. http://council.blackburnworld.com/council/executive_board/executive_board_documents/ 011204/html/faith_schools_brief.htm. Most recently accessed September 4, 2003. 